\title{
Innovative Knowledge Management At Disney: Human Capital And Queuing Solutions For Services
}

\author{
Rachelle F. Cope, Southeastern Louisiana University, USA \\ Robert F. Cope III, Southeastern Louisiana University, USA \\ Anna N. Bass, Southeastern Louisiana University, USA \\ Holly A. Syrdal, Southeastern Louisiana University, USA
}

\begin{abstract}
It is well known that most activities in which a service is provided require customers to wait in a queue during the experience. One thing that is inherent in waiting lines is the universal dislike for the process. In fact, the feelings and opinions developed in waiting lines influence the customer's perception of the awaited experience. In this paper, Disney is used as a case study for queuing solutions. In particular, we examine their implementation of Knowledge Management (KM) solutions to improve the waiting line process. The use of Disney cast members as human capital combined with the knowledge of customer preferences has made the FASTPASS an innovative solution to enhance queuing in the Disney theme parks. In the past, KM has been thought of as the collection of technological assets and managerial policies that compensate for information failures. In fact, the individual's need for human interaction provides the richest opportunity for knowledge acquisition. Disney's ability to capture customers in virtual queues while giving them a pleasurable waiting experience has made them a leader in KM initiatives in the service industry.
\end{abstract}

Keywords: knowledge management, human capital, queuing, FASTPASS, virtual queue

\section{INTRODUCTION}

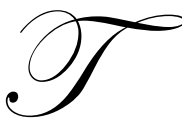

he concept of Knowledge Management (KM) has been around for decades, but most organizations accept it only as theory and have not implemented it. It has been difficult for many firms to evolve their organizational thinking from an information focus to a knowledge focus. Throughout the past several decades, information systems practices were sufficiently developed to accomplish efficient information production. Information was abundant, but problems arose when key individuals possessing pertinent knowledge did not, or would not, share it with others who stood to benefit from its discovery.

The Gartner Group, an international technology consulting group, defines KM and offers it as a discipline that encourages a mutually supported method to create, capture, organize, and use information (Duffy, 2000). From a more intuitive standpoint, it is using whatever means possible to compensate for the fact that most organizations are too big for everyone to know each other and share information at a person-to-person level (Novins, 2000). Therefore, necessary incentives must be put into place in order for KM to be viewed by firms as an asset that goes beyond the value of their available information.

In our work, we explore the topic of KM in action at Walt Disney World. In particular, we examine Disney's emphasis on human capital within their theme parks, combined with traditional queuing theory to create more pleasurable waiting environments. These KM practices are strategically used in order for Disney to capitalize on situations which would otherwise lead to loss of customer satisfaction. We will discuss the practices used by Disney to enhance goodwill and profitability, and we will generalize these concepts for other service organizations. Thus, this paper will show the value of tacit employee knowledge integrated with traditional queuing theory. The marriage of these two initiatives creates an innovative solution. 


\section{KNOWLEDGE MANAGEMENT BASICS}

Dunn and Neumeister (2002) provide a synopsis of the evolution of KM. They postulate that instances of KM may have been recognized first around the time of World War II. It was during this period that it became evident how workers learned from experience. For instance, it was noticed that building a second airplane took considerably less time than building the first. Nobel Prize-winning economist Kenneth Arrow (1962) addressed the issue of learned experience (i.e., KM) in his article entitled "The Economic Implications of Learning by Doing." During this same time period, resources began to be devoted to the cause of determining significant performance variations in output within organizations.

Attempts to increase organizational learning in the 1970s and 1980s included Information Management and Total Quality Management. Another practice called "Human Capital Movement" also arose during this time frame and is based on the belief that investment in individuals through education and training has a high rate of return. Although it is unclear when the term "Knowledge Management" was officially coined; the concept intensified in the 1990s. Karl Wiig (1993) authored "Knowledge Management Foundations: Thinking about Thinking - How People and Organizations Create, Represent and Use Knowledge," which was possibly the first published use of the term.

Dunn and Neumeister (2002) define KM as a systematic approach to managing and leveraging an organization's knowledge assets, which may include knowledge of the organization's customers, products, markets, processes, finances and personal services. Novins (2002) shortens the definition to simply say that KM can be thought of as packaging the right content and delivering it to the right people who can make use of it at the right time. Koskinen's (2004) work categorizes KM into two components to support communication and implementation in management. First, he defines explicit knowledge as knowledge that can be embodied in a code or a language, and, as a consequence, can be communicated easily. The code may be words, numbers, or symbols such as grammatical statements, mathematical expressions, specifications, and manuals. In addition, he defines tacit knowledge as knowledge based on the experience of individuals. It expresses itself as human actions in the form of evaluations, attitudes, points of view, commitments, motivation, etc. Some have summarized tacit knowledge by the phrase, "We know more than we can tell." To simply distinguish between the two, explicit knowledge is about why things work, and tacit knowledge is about what things work.

The effective use of KM involves a systematic process of finding, selecting, organizing, distilling and presenting information in a way that improves an employee's comprehension in a specific area. Ultimately, people must be enabled to collaborate with one another through the use of KM. The ability to let individuals share their ideas is an integral part of a meaningful KM solution.

\section{KNOWLEDGE MANAGEMENT CHARACTERISTICS AND ROLES}

In an e-Business presentation, Peter Novins (2002), a vice president at Cap Gemini Ernst \& Young, summarized the characteristics of KM. He asserted that good KM should have three characteristics:

- $\quad \mathrm{KM}$ needs to address a real business problem that everybody agrees is a problem.

- An organization cannot sustain a KM system without some kind of community interest or practice that provides content and accepts responsibility for continuing to build and share that content.

- $\quad$ KM systems have to make it very easy for people to get the content they need.

as:

In addition, O’Dell (2004) describes the three roles of a KM system. These roles are identified and defined

- Knowledge Steward: One who collects, analyzes, and organizes knowledge held by individuals within an organization.

- Knowledge Facilitator: One who establishes connections between individuals in order to share knowledge.

- Community of Practice Leader: One who sets the direction and climate for knowledge sharing in the community and ensures that both the organization and all of its members are benefiting from the exchange. 
To successfully apply these characteristics and roles, it is important for organizations to realize that KM will not happen without sufficient resources. Such resources should be dedicated to the task of making information sharing possible.

\section{THE VALUE OF HUMAN CAPITAL AT DISNEY}

As stated by Bob Norton, "One of the things that is intriguing about Disney is the measures that they take to insure customer delight as opposed to customer service. This means going far beyond customers' expectations and the call of duty to deliver something special." Norton is the President and CEO of C-Level Enterprises, a company providing executive training and consulting services. Norton's comments reinforce the concept that Disney is practicing the KM principle of rewarding employees who actually execute magic moments. In her 2010 Line Zine interview, Cheryl Emory states, "Leaders agree that human capital (the people, the knowledge, the ideas, the creativity) may be today's most valuable commodity. In the same interview, Larry Lynch talks about the fact that Walt Disney understood the value of the human component. Disney believed that it is the everyday interaction between Disney cast members and guests that genuinely makes the difference. This is why Disney has sought to continually enhance the customer's experience. This organization knows that customers who leave Disney theme parks with memories of experiences that exceeded their expectations will return again and again. Continuing their goal of creating "magical moments," Disney has evolved their initial human capital initiative into one that integrates Operations Research. In particular, the efforts of the cast members are enhanced by FASTPASS, Disney's virtual queue.

\section{QUEUING SYSTEM BASICS FOR SERVICES}

In quantitative methods terminology, a waiting line is also known as a queue, and the body of knowledge dealing with waiting lines is known as Queuing Theory. In the early 1900s, A. K. Erlang, a Danish telephone engineer, began a study of congestion and waiting times occurring in the completion of telephone calls. Since then, queuing theory has grown far more sophisticated with applications in a wide variety of waiting line situations.

The basic components of a waiting line are its customers, calling population, arrival rate, servers, service rate, queue discipline, queue length, channels, and phases. The following are brief descriptions of each of these components (Cope et al., 2008).

Customers: A customer is a person or thing that wants service from an operation.

Arrival Rate: The arrival rate is the frequency (number per given period of time denoted by $\lambda$ ) at which customers arrive at a service facility according to a probability distribution (e.g., Poisson).

Servers: A server is a person or thing that performs a specific, requested operation.

Service Rate: The service rate is the frequency (number per given period of time denoted by $\mu$ ) at which customers are being served by servers at a service facility according to a probability distribution (e.g., Exponential).

Queue Discipline: A queue discipline represents the order in which customers are served. (e.g., first come, first served)

Queue Length: Queues can be of an infinite size (no upper size limit) or finite size (constrained upper limit) in length.

Channels: Channels represent the number of parallel servers available for a customer to receive service.

Phases: Phases denote the number of sequential servers a customer must go through to receive service.

Hillier and Lieberman (2001) derive a variety of mathematical relationships for waiting line models using D. G. Kendall's three-symbol notation. Such models can be used to determine the operating characteristics (performance measures) of a queue. Common operating characteristics include the following:

- $\quad$ The probability that no units are in the system (Po)

- $\quad$ The average number of units in the waiting line $(\mathrm{Lq})$

- $\quad$ The average number of units in the system (L)

- $\quad$ The average time a unit spends in the waiting line (Wq)

- $\quad$ The average time a unit spends in the system (W)

- The probability that an arriving unit has to wait for service (Pw) 
Hillier and Lieberman (2001) also showed that the mathematical relationships used do not necessarily provide an optimal, or "best" case solution. Instead, the formulas generate measures that explain the performance of the system. It is assumed that these measures approach constant, average (steady-state) values after the system has been in operation for a long time.

Though not an exhaustive list, several common queuing models for services are presented by Taylor and Taylor (1998). Interestingly, most of Disney's attractions can be classified into one of these queuing systems:

Single-Channel, Single-Phase System: Known as the most common model, it is described as a waiting-line model where steady-state operation results from arrivals that follow a Poisson probability distribution, service times that follow an Exponential probability distribution, infinite queue length, and a first-in-first-out queue discipline.

Single-Channel, Multi-Phase System: This model can be described as a series of independent, Single-Channel, Single-Phase systems, where the completion of each phase is necessary for completion of the service.

Multi-Channel, Single-Phase System: This model has the same assumptions as the Single-Channel, Single-Phase system, except that there are several independent servers in parallel to assist customers with their service requirements.

Multi-Channel, Multi-Phase System: In this model, the same assumptions as the Multi-Channel, Single-Phase system are assumed, except that there are several servers within several phases available to assist customers with their service requirements.

It is not surprising that many queuing systems in business can also be classified into one of these categories. The next step to efficiency in service, according to Disney, is to bundle services in a reservation system or virtual queue.

\section{MANAGING THE PERCEPTION OF WAITS}

Rather than managing the arrivals of the queue, the perception of the wait can be managed. From the customer's standpoint, satisfactory waits can create goodwill, says Maister (1985). However, unsatisfactory waits can earn firms a bad reputation, resulting in little return business. Much research has been performed on wait perception, leading to the following statements of influence organized by Dickson, et al. (2005):

- $\quad$ Unoccupied time feels longer than occupied time.

- $\quad$ Anxious, sad, and angry waits feel longer than relaxed ones.

- Waits of uncertain length feel longer than certain ones.

- $\quad$ Unexplained waits feel longer than explained waits.

- Uncomfortable waits feel longer than comfortable waits.

- Unfair waits feel longer than fair ones.

Another design principle of waiting lines is that emotions dominate (Norman, 2008). Some feel that this is the most important and critical issue in waiting line principles. Emotions color the experience and, more importantly, how the experience will be remembered. The memory of an event may be even more important than the event itself. With this in mind, Disney uses both cast members and waiting line strategies to make "magical memories."

\section{DISNEY'S SERVICE ISSUE AND SOLUTIONS}

Disney managers have long understood the pressures of waiting time vs. revenue; they know that every minute spent waiting in line is a minute that the customer is not generating revenue. Consequently, Disney has continuously attempted to optimize revenue by balancing the costs of capacity and the costs of not having adequate capacity to serve customers as they attempt to enjoy the service experience. In spite of their apprehension, Disney managers have proceeded with the design of a reservation system for their attractions. By definition, the virtual queue-waiting strategy recognizes that guests can be freed from physically standing in line by being placed in a virtual queue, which eliminates both the actuality and perception of waiting by allowing guests to engage in other productive and enjoyable activities until their time to be served has arrived (Dickson et al., 2005). 
The system was first tested at Walt Disney World in 1998. Managers assessed the system by surveying guests who used it. Results were positive and indicated that guests spent substantially less time in lines, spent more per capita, and saw significantly more attractions. Satisfaction levels skyrocketed.

The system was expanded in 1999 to include five of the most popular park attractions and was named FASTPASS. The system has since been expanded to all Disney theme parks worldwide, and is now in use by over 50 million guests per year.

An important feature of the system is that guests have two options when approaching a FASTPASS attraction. Namely, they can choose to:

1. obtain a FASTPASS ticket and come back at a later, designated time, or

2. wait in a traditional line.

Guests are assisted in making their choice by information regarding estimated waits of both options. Thus, they can decide to wait in the traditional line, or take a FASTPASS ticket and return at a later time with no further wait. These published wait times also serve to self-regulate and stabilize the system.

To ensure that guests feel comfortable in using valuable wait time to do other things, FASTPASS designers added some flexibility into the system. Once an assigned FASTPASS time is generated and provided to a guest, it is valid for the 60 minutes beyond that time, creating a "window" in which guests can return.

There are numerous benefits in allowing park guests to return to an attraction within a designated time frame. Waits involve managing two major customer issues: (1) How long people actually wait, and (2) how long they think they are waiting. When park guests are allowed to divert their attention to other activities, there is the perception that there is no wait.

The key feature of the FASTPASS systems is choice. A quick survey of an attraction's queue allows guests to pick the shorter wait and move on to something else. Disney managers knew that the queues were self-regulating, but were perplexed as to why some guests actually chose traditional waits. They soon learned that those who chose traditional waits were most often holding FASTPASS tickets for another attraction. Thus, customers were allowed the ability to see two attractions during the time they would have previously been able to see only one.

This can be viewed as an implementation of a multi-phase system. Depending on the attractions picked, each queue may be single-channel or multi-channel. However, when combining two or more service attractions, the guest creates his or her own multi-phase system. Obvious results were that guests were able to engage in more revenue-producing activities, saw more of the popular attractions, and began to partake in other less utilized attractions (Cope et al., 2008).

In addition, Disney parks are producing an additional form of revenue via KM principles. Customers holding FASTPASS tickets may choose to visit a gift shop or buy park concessions. Thus, Disney has the ability to bundle and possibly co-branded products and services.

\section{DISNEY'S APPROACH COMBINING QUEUING AND HUMAN CAPITAL}

Disney has provided an interesting study that combines the techniques of queuing and human capital to strategically leverage $\mathrm{KM}$ in their organization. Often, these two initiatives are treated independently in organizations. The use of the FASTPASS provides an insightful application of the combination of these two principles. While waiting lines are an unavoidable part of the Disney experience, park guests build "magical memories" through innovation. Disney's belief in human capital is evident from the moment a park guest steps into a park. It is Disney's recognition of cast members as human capital that transforms their employees into Knowledge Facilitators who multitask in their roles. For example, an attraction host or a street sweeper may be a valuable source of knowledge to park guests. In addition to their primary roles, they may have a wealth of information about 
attractions for bewildered guests. They may be able to give directions, provide schedules, and offer helpful suggestions from their daily observations. This is the first step to increased knowledge management.

Next, Disney improves its customers' perception by minimizing the perception of waits. The use of the FASTPASS enables Disney not only to enhance the psychological aspect of waiting lines, but also to capitalize at the same time. In this respect Disney is taking the role of Knowledge Steward. Through an in-depth analysis of customer preferences, Disney managers have turned a queuing problem into a KM solution. It is also evident that the Disney organization sets the climate for knowledge sharing. In their quest for "magical memories," Disney is allowing valuable collaboration to take place. Thus, the third role of Community of Practice Leader is achieved.

\section{CONCLUDING REMARKS}

Providing insight into the study of KM through the examination of the Disney FASTPASS, our work presents a foundation for the development of strategies that may enhance KM in service industries. As stated by Novins (2002), "The solution isn't creating the world's greatest database repository of all wisdom with the world's fanciest search engine. Instead, we need to give people specific tools designed to help them do their job and solve specific business problems." Human Capital and Queuing Theory provide two very different, but valuable, assets in service organizations. When combined, they provide a synergistic form of knowledge management that successfully implements the three roles of KM. The correlations discussed here provide the opportunity to continue this research and to offer further study of combined strategies for effective KM in service industries.

\section{AUTHOR INFORMATION}

Dr. Rachelle Cope is a Professor of Information Systems at Southeastern Louisiana University in Hammond, Louisiana. She received a Ph.D. in Business Administration in 1996 from Louisiana State University with a concentration in Information Systems and Decision Sciences. She currently teaches courses in Business Statistics, Principles of Supply Chain Management, and Data Management for Business. Her research interests include software reliability improvement warranties, dynamic storage reallocation, linear Diophantine analysis, knowledge management, and organizational citizenship behavior. Contact her at rcope@ selu.edu.

Dr. Robert Cope is a Professor of Operations Management and Interim Department Head for Marketing and Supply Chain Management at Southeastern Louisiana University in Hammond, Louisiana. He received a Ph.D. in Business Administration in 1998 from Louisiana State University with a concentration in Information Systems and Decision Sciences. He currently teaches courses in Management Science, Project Management, and Logistics Management and Transportation. His research interests include resource optimization techniques, scheduling, statistical modeling, and the design of information technology. Contact him at rcope2@selu.edu.

Ms. Anna Bass is an Instructor of Management at Southeastern Louisiana University in Hammond, Louisiana. She earned an MBA from Southeastern in 2001, and has been with the University for over twenty years. She currently teaches courses in Organizational Behavior and Principles of Management. Her research interests include human capital development through professional presence and business etiquette. Additionally, she serves as an executive etiquette consultant to business and civic organizations in the Baton Rouge and New Orleans areas. Contact her at abass@selu.edu.

Ms. Holly Syrdal is an Instructor of Marketing at Southeastern Louisiana University in Hammond, Louisiana, where she received an MBA in 2006. She currently teaches courses in Public Relations, Advertising and Principles of Marketing. Her research interests include consumer behavior, public relations, and the utilization of social media for marketing purposes. She has a strong interest in service-learning, and has incorporated such projects and case studies into the courses she teaches. Contact her at Holly.Syrdal@selu.edu. 


\section{REFERENCES}

1. Arrow, K. (1962). The Economic Implications of Learning by Doing. Review of Economic Studies, 29 (June), 155-173.

2. Cope, R., R. Cope and H. Davis (2008). Disney's Virtual Queues: A Strategic Opportunity to Co-Brand Services? Journal of Business \& Economics Research, Vol. 6, No. 10, 13-20.

3. Dickson, D., R. Ford and B. Laval (2005). Managing Real and Virtual Waits in Hospitality and Service Organizations. Cornell Hotel and Restaurant Administration Quarterly, Vol. 45, No. 1, 52-68.

4. Duffy, J. (2000). Knowledge Management: To Be or Not to Be? Information Management Journal, Vol. 34, No. 1, 64-67.

5. Dunn, J. \& A. Neumeister (2002). Knowledge Management in the Information Age. E-Business Review, Fall, 37-45.

6. Emory, C. (2010). The Disney Approach to Human Capital. Interview Article from Line Zine, November 13, 2010, http://www/clevelenterprises.com.

7. Hillier, F. and G. Lieberman (2001). Introduction to Operations Research. $7^{\text {th }}$ edition, McGraw-Hill, New York City, New York.

8. Maister, D. (1985). The Psychology of Waiting Lines within The Service Encounter: Managing EmployeeCustomer Interaction in Service Businesses, edited by J. Czepiel, M. Solomon and C. Suprenant, Lexington Books, Lexington, Massachusetts.

9. Novins, P. (2002). Knowledge Management for Competitive Advantage and Shareholder Value. EBusiness Review, Fall, 33-36.

10. O'Dell, C. (2004). The Executive's Role in Knowledge Management. American Productivity and Quality Center: Houston, TX.

11. Taylor R. and B. Taylor III (1998). Operations Management: Focusing on Quality and Competitiveness. $2^{\text {nd }}$ edition, Prentice Hall, Upper Saddle River, New Jersey.

12. Wiig, K. (1993). Knowledge Management Foundations: Thinking about Thinking. How People and Organizations Create, Represent and Use Knowledge. Vol. 1 of Knowledge Management Series. Schema Press: Arlington, TX. 


\section{NOTES}

